\title{
EL NEOPOLICIAL CUBANO DESCIENDE A LOS INFIERNOS: La pentalogía de AMIR Valle
}

\author{
CUBAN NEOPOLICIAL DESCENDS INTO THE UNDERWORLD:
}

AMIR VAlLE'S PENTALOGY

Carlos Uxó González

Monash University

Melbourne, Australia

\section{Resumen}

Entre los años 2001 y 2008 el escritor cubano Amir Valle publicó las cinco novelas de la serie "El descenso a los infiernos", con la cual se convertía en uno de los narradores de novela negra más célebres de las últimas décadas en Cuba. Escrita, en cierto modo, como continuación narrativa de su controvertido Habana Babilonia, la serie continúa su acercamiento al mundo de la marginalidad habanera, con el propósito de denunciar lo que el autor considera es el fracaso revolucionario. El artículo examina hasta qué punto el proyecto de Amir Valle resulta exitoso, seńalando al mismo tiempo problemas como la representación racial o cierta tendencia a la politización excesiva del discurso.

Palabras claves: Cuba, neopolicial, marginalidad, novela negra, personajes afrocubanos.

\section{Abstract}

Between 2001 and 2008 Cuban writer Amir Valle published the five novels of his series "The descent into the underworld", with which he became one of the most famous crime fiction writers of the last decades in Cuba. Written as a narrative continuation of his controversial Habana Babilonia, the series continues its approach to the world of Havana's marginality with the purpose of denouncing what the author considers the failure of the Cuban Revolution. The article examines to what extent Amir Valle's project is successful, pointing out at the same time problems such as racial representation or his tendency toward an excessive politicization of the discourse.

Keywords: Cuba; neopolicial; marginality; crime fiction; Afro-Cuban characters.

\section{Resumo}

Entre 2001 e 2008, o escritor cubano Amir Valle publicou as cinco novelas da série "A descida para o submundo", com a qual se tornou um dos narradores mais famosos das últimas décadas em Cuba. Escrita, de certa forma, como uma continuação narrativa de sua controvertida Habana Babilonia, a série continua sua aproximação ao mundo da marginalidade havanesa, com o objetivo de denunciar o que o autor considera ser o fracasso revolucionário. $\mathrm{O}$ artigo examina até que ponto o projeto de Amir Valle é bem sucedido, indicando ao mesmo tempo problemas como a representação racial ou a tendência à politização excessiva do discurso.

Palavras-chave: Cuba, neopolicial, marginalidade, ficção criminal, personagens afro-cubanos. 
Entre los años 2001 y 2008 el escritor cubano Amir Valle publicó la serie "El descenso a los infiernos", con la cual se convertía en uno de los escritores de novela negra (término preferido por el autor) más célebres de las últimas décadas en Cuba. La serie nacía al albur del éxito de su controvertido libro Habana Babilonia o Prostitutas de La Habana (primera versión, 1999), para el cual Valle había amasado una ingente cantidad de información que entendió que no podía integrar en un solo volumen. Como aquel, las novelas bucean en el mundo marginal habanero con la intención explícita de visibilizar una parte de la realidad cubana ausente de la prensa nacional. No obstante, si Habana Babilonia se centraba en la prostitución (o el jineterismo, usando el término cubano), "El descenso a los infiernos" lleva al lector a un mundo cada vez más sórdido, que incluye la explotación sexual de niños, el narcotráfico, la prostitución homosexual bajo chantaje, el tráfico de personas y una rampante corrupción. Igualmente, la serie subvierte el entendimiento oficial de la justicia y propone una nueva conceptualización de la marginalidad, percibida como esfera alternativa y necesaria a lo que Valle entiende como el fracaso revolucionario: frente a un gobierno negligente, que crea penuria y desesperación, a los ciudadanos de Centro Habana no les queda sino recurrir a las soluciones que aporta la marginalidad, insiste repetidamente el escritor.

El artículo que sigue no trata, desde luego, de argumentar a favor o en contra del fracaso revolucionario cubano, sino que analiza el alcance literario de las novelas de Amir Valle, partiendo de un punto que considero esencial para entender la serie: su inserción en la narrativa cubana en su triple condición de novelista policial, escritor de la marginalidad y autor del denominado grupo de los Novísimos. La interrelación de estas perspectivas facilitará el entendimiento integral de la serie, en relación a la tradición narrativa en que se inserta y al contexto concreto al que responde.

Comencemos por retrotraernos al año 1992. El colapso de la Unión Soviética había arrastrado al bloque socialista a un abismo que en Cuba viene a conocerse como Periodo Especial en Tiempos de Paz. La colosal crisis económica provoca primero una escasez generalizada de cuanto pueda imaginarse y, de inmediato, una desmoralización cada vez más desesperada que golpea con más fuerza a los sectores más desfavorecidos. El gobierno, a marchas forzadas, busca posibles soluciones y recurre al turismo. En las calles de Centro Habana la población busca posibles soluciones y recurre a los turistas. El crecimiento del jineterismo es exponencial.

Por casualidad, un joven, Amir Valle (Guantánamo, 1967), escritor multilaureado del grupo de los Novísimos, coincide por entonces con una antigua amiga, ahora jinetera, y tras una breve charla con ella decide iniciar una investigación sobre el mundo de la prostitución en Cuba. Siete años más tarde, el resultado es un manuscrito que bajo el título de Habana Babilonia o Prostitutas en Cuba presenta, en la categoría de testimonio, al premio Casa 
de las Américas. El premio es declarado desierto, pero el manuscrito pasa a la historia de la literatura cubana cuando un desconocido cuelga una copia en internet, convirtiéndolo de la noche a la mañana en un fenómeno cultural, quizás lo que hoy denominaríamos el primer viral de Cuba. ${ }^{1}$

El impacto de Habana Babilonia fue incuestionable, aunque no siempre positivo. Para Gilberto Padilla (2015), el éxito supuso que se convirtiera "en un virus literario que infectaba primero a los periodistas y luego provocó algunas metástasis en el cine cubano". A su estela, añade, surgieron "malísimos epígonos" que formaban parte de "una irritante lista de intentos de destronar a Amir Valle del centro del non-fiction", haciendo que "en la discoteca de nuestra narrativa" Centro Habana llegara a sonar

como un viejo hit remasterizado. $\mathrm{Y}$ a los extranjeros les suena perfecto. Basta tararear un poco y seguir el ritmo para ver cómo aparecen Gutiérrez, Valle, y hasta Padura, todos de traje y corbata negra, onda Reservoir Dogs, caminando en cámara lenta hacia el desastre 100 por ciento cubano" (PADILLA, 2015, s.p., párrafo 5).

Por momentos parece que Padilla incluye entre esos epígonos injustificables a la serie policial del propio Valle, al cual acusa de no haberse podido recuperar de aquel éxito:

Ningún otro texto de Amir alcanzó la misma cotización de remate que Habana Babilonia. El esfuerzo de muchos por conseguir otras de sus novelas es un espejismo, la ratificación del efecto que Habana Babilonia les produjo. Destino trágico el de Amir Valle: sus lectores en Cuba, al parecer, son los lectores vacantes de Pedro Juan Gutiérrez (PADILLA, 2014b, s.p., párrafo 6).

Para cuando Habana Babilonia se publica en 2006 en México (en Cuba se había convertido en un producto intocable), ya habían aparecido las tres primeras novelas de la serie (Las puertas de la noche, 2001; Si Cristo te desnuda, 2001; Entre el miedo y las sombras, 2003) así como el relato Últimas noticias del infierno (2005). Estos textos habían provocado una creciente tirantez con la oficialidad cultural cubana y, cuando se publica la cuarta novela, Santuario de sombras (2006), la tensión es tal que, tras la presentación del libro en Alemania, Amir Valle permanece en ese país, donde reside hasta hoy día. En 2008 se publicó la quinta novela de la serie, Largas noches con Flavia, permaneciendo inédita hasta hoy Nudos invisibles, de la que apenas se han publicado unas páginas, y que habría de concluir "El descenso a los infiernos".

1 Sobre el robo del manuscrito y sus consecuencias, ver Valle, "De jineteras a la serie 'el descenso a los infiernos". Sobre el problema con el premio Casa de las Américas y el papel desempeñado por Miguel Barnet, ver Añel, "Censura y autocensura", p. 77. 
Como mencioné anteriormente, el autor pertenecía a los llamados Novísimos, la primera generación de escritores nacidos tras el triunfo revolucionario de 1959. Con un incuestionable afán de renovación teñido de posmodernismo iconoclasta, este grupo de jovencísimos escritores (muchos de ellos no llegaban a los veinte ańos cuando empezaron a acumular premios literarios a nivel nacional) comenzó a destacarse ya desde finales de los ochenta, aunque su explosión se produce en los convulsos noventa. Siguiendo la estela renovadora de los llamados Nuevos (entre los cuales se encontraba quien se convertiría en la figura indiscutible del neopolicial cubano, Leonardo Padura), los Novísimos enfatizan su desviación del canon oficial incorporando nuevas formas, nuevos temas y, sobre todo, remarcando el carácter performativo de la literatura, que se percibe no sólo como ligada a la sociedad, sino como agente de cambio social en tanto que opuesta a la verdad que emana del todopoderoso centro. ${ }^{2}$ Para cuando estalla la crisis del Periodo Especial, los Novísimos arremeten con una narrativa directa y sin ambages, en cuyo centro se sitúa, quizás como gran personaje, al marginal, entendido genéricamente, en un sentido mucho más amplio que el que luego aplicará Valle en su novela negra, como cualquier individuo que se siente desterrado del contexto social mayoritario cubano: homosexuales, roqueros, artistas alternativos, enfermos de SIDA o fumadores de marihuana.

Es en este contexto en el que se puede entender mejor el atractivo que Amir Valle sintió por el neopolicial, una variación genérica que, en el caso cubano, suponía un abierto desafío a la oficializada novela policial revolucionaria. Ésta había surgido a principios de la década de los setenta, con el propósito explícito de mostrar la labor de las fuerzas de seguridad cubanas en su lucha contra el capitalismo y fomentar el apoyo popular a las mismas. Intensamente politizada, la novela policial revolucionaria se movía dentro de unos parámetros cada vez más estrictos que llevaron ineludiblemente a la reiteración de unas fórmulas que, con contadas excepciones, acabaron por imposibilitar cualquier desarrollo literario de interés. ${ }^{3}$ Además de tramas cada vez más predecibles, cabe señalar aquí dos deficiencias que el neopolicial cubano no evita. Por un lado, la muela o el teque, expresiones cubanas que en este caso se refieren a la ubicuidad del discurso político oficial, introducido en las novelas de manera forzada, con excesiva reiteración o extensión y sin ningún tipo de enfoque crítico. Por otro lado, un lenguaje acartonado y poco ajustado a la realidad que, si queda lejos del habla coloquial cubana, resulta ridículo a la hora de darle voz al mundo de la delincuencia.

A contrapelo de un policial cada vez más rancio y de reducida popularidad, Leonardo Padura lanza a principios de los noventa la serie

2 El propio Amir Valle ha escrito uno de los análisis más completos sobre los Novísimos: Brevísimas demencias. La narrativa joven cubana de los 90.

3 Entre las excepciones destacan las novelas de Justo Vasco, por quien Valle ha declarado su admiración. 
"Las cuatro estaciones" (1991-1998), que acabará teniendo un impacto extraordinario en la literatura cubana. No es este el momento de referirnos al fenómeno Padura, en la actualidad el autor cubano con mayor proyección (y ventas) dentro y fuera de la isla. Lo que interesa reseñar, no obstante, es el cambio de dirección que provoca en el policial cubano, que abandonará el carácter hagiográfico para convertirse en una indagación del lado sombrío de la vida revolucionaria, de las zonas oscuras invisibles (o invisibilizadas). ${ }^{4} \mathrm{Si}$ hasta entonces el policial cubano se había concebido como un arma en la lucha contra el capitalismo, Padura lo transforma, en consonancia con la evolución del neopolicial latinoamericano, en una herramienta para reconsiderar el pasado, develar las imperfecciones del presente y aventurar el posible destino del país. El éxito editorial y las posibilidades de la nueva fórmula atrajeron de inmediato a numerosos escritores, entre los cuales destacan Lorenzo Lunar Cardedo y el propio Amir Valle.

La procedencia del grupo de los Novísimos y el nacimiento del neopolicial cubano se combinan con un tercer elemento que resulta de interés para entender la serie del descenso a los infiernos: la relevancia que a partir de la década de los noventa adquiere la temática de la marginalidad en las ciencias sociales y la literatura cubana. ${ }^{5}$

Tras el triunfo de la Revolución, el gobierno cubano había adoptado un modelo socialista que asumía un objetivo abarcador y absoluto: integrar en el proceso revolucionario a la totalidad de la ciudadanía. Dicho modelo priorizaba la homogeneidad y ambicionaba borrar cualquier remanente del capitalismo, entre los cuales incluía la marginalidad. Al aplicar una aplastante lógica marxista, según la cual una vez derrotado el capitalismo quedaban obliterados todos los fenómenos asociados al mismo, pasó a considerarse que carecía de sentido cualquier debate, análisis o narrativa sobre la marginalidad. Lo que de ella quedaba, no eran más que vestigios de un sistema en vías de extinción y, por tanto, inconsecuente para el quehacer revolucionario. El consiguiente silenciamiento del problema y su efecto negativo serían reconocidos en el año 2000 por Fidel Castro:

Tiempo tardamos en descubrir [...] que la marginalidad [...] es algo que no se suprime con una ley ni con diez leyes, y aún en cuarenta años nosotros no hemos logrado suprimirla totalmente [...] Hay zonas marginales, hay cientos de miles de personas que viven en zonas marginales (CASTRO, citado en HERNÁNDEZ, 2001, p. 100).

\footnotetext{
4 Si bien el policial hagiográfico no ha desaparecido por completo en Cuba y continúa parapetado en la Editorial San Luis del Ministerio del Interior, su alcance, relevancia y seguimiento son prácticamente nulos.

5 En el contexto de este artículo no deben confundirse el personaje del marginal y la marginalidad. El primero se refiere a un individuo que no está plenamente integrado a la masa mayoritaria, de la cual se siente ajeno por cualquier motivo. La marginalidad implica una combinación en distintos grados de precariedad y actividades ilegales, como la compraventa en el mercado negro o el proxenetismo.
} 
Cuando Fidel pronuncia estas palabras, ya la narrativa cubana había ido incorporando la problemática de la marginalidad. Autores como Sergio Cevedo o Guillermo Vidal primero, y más tarde Pedro Juan Gutiérrez, Ronaldo Menéndez, el ya mencionado Lorenzo Lunar o el propio Amir Valle, entre otros, se acercan a este tema atraídos por la zona conflictiva en que se mueve y por las posibilidades críticas inherentes a él. De lo que se trata no es ya de culpabilizar a los habitantes de esa marginalidad, como remanentes del capitalismo no incorporados al proceso revolucionario, sino de indagar en las condiciones que la hacen posible y en los mecanismos de supervivencia de quienes se ven abocados a vivir en ella.

La combinación de su trayectoria como Novísimo, del nacimiento del neopolicial en Cuba y del auge de la temática de la marginalidad conduce a Amir Valle, de forma casi inevitable, a escribir su primera novela, Las puertas de la noche, con la que inicia la serie del descenso a los infiernos.

Cuestionado sobre su decisión de escribir una novela negra, el escritor ha comentado que fue tras mantener unas conversaciones con Leonardo Padura y Paco Ignacio Taibo II cuando se convenció de la posibilidad que le ofrecía el género de superar los dos paradigmas imperantes en la novelística cubana (Alejo Carpentier y Lezama Lima). La novela negra, pensó, le permitía una mayor libertad, así como la posibilidad de jugar más con la estructura y las figuras literarias (FERNÁNDEZ y OFFERDAHL, 2009, p.154). No obstante, consciente sin duda del peso específico de Leonardo Padura, Valle tuvo claro desde el principio que su proyecto debía ser distinto del de aquél. El centro de la novelística de Padura, dice Valle, lo ocupan sus personajes, cuyos conflictos existenciales acaban por ser más importantes que los hechos que se investigan. El resultado, añade, es un "esquema bastante aéreo del tema en cuestión" que resulta en una crítica "mucho menos peliaguda para la isla". Su objetivo era diferente, era

poner a vivir al barrio... de Centro Habana tal cual él es, con toda su podredumbre, con todas sus miserias, con el tráfico de droga, con la prostitución, con la gente de la doble moral, con el discurso cotidiano que tiene la gente (FERNÁNDEZ y OFFERDAHL, 2009, p.155).

De manera implícita, Valle considera su acercamiento mucho más crítico que el de Padura, a quien parece estar recriminando cierta levedad (y, extrañamente, la preponderancia de lo literario sobre lo político). Al mismo tiempo, el escritor ha insistido que en todo caso su afán ha sido siempre "no escribir una literatura crítica, donde se vieran las costuras de lo ideológico o de mis deseos de criticar lo mal hecho" (VALLE, 2013, s.p., sección 3 párrafo 3). Lamentablemente, a pesar de haberse planteado tal objetivo, lo 
cierto es que con frecuencia la serie adolece precisamente de un discurso excesivamente politizado que llega a anteponer la función crítica a la función estética de la literatura.

Un componente fundamental del acercamiento crítico del proyecto de Valle es su insistencia en la veracidad de los hechos narrados, la cual basa tanto en la prolongada investigación del mencionado Habana Babilonia, como en su propia experiencia personal, a la que se ha referido tanto en entrevistas como en las novelas mismas. En este sentido, el escritor se incluye a sí mismo como integrante de la marginalidad sobre la que escribe:

cuando empecé a investigar [Habana Babilonia] vivía como un paria en la capital. Acababa de llegar de Cienfuegos y no tenía ni siquiera un techo, de modo que tuve que vivir de la caridad de algunos amigos escritores de mi generación, o en alquileres ilegales, y no niego que hubo días en que tuve que dormir en las terminales de ómnibus o de trenes (VALLE, 2007, s.p., sección Los espacios, párrafo 1).

De manera similar a como hiciera Pedro Juan Gutiérrez, ${ }^{6}$ Valle narrativiza su propia vida para dotarla de un aura de pseudolegalidad y ofreciéndose como icono de la marginalidad. "Yo he estado ahí y sé de lo que hablo", parece decir en numerosas ocasiones. Entrevistado por el también escritor Ángel Santiesteban cuenta cómo hubo de recurrir a la venta de tabaco y piezas de computadoras robadas (SANTIESTEBAN, 2015). En otros textos ha recordado que durante un año vivió en la casa de la madre de una jinetera y más tarde lo hizo en "uno de los barrios más problemáticos de Centro Habana” (VALLE, 2007, s.p., sección Los espacios, párrafo 1), que él "mismo, viviendo los avatares de la marginalidad... [fue] una víctima. Y vivía rodeado de esas víctimas que jamás serán noticia", de voces que le decían "tú eres uno de los nuestros, mira cómo te vistes, mira cómo haces colas igual que nosotros, cómo compras en el mercado negro" (VALLE, 2013, s.p., sección 3, último párrafo).

Por lo que respecta al discurso autorreferencial dentro de las novelas, cabe comentar que había sido rasgo característico de la narrativa de los Novísimos. No resulta difícil encontrar en estas, alusiones de los escritores a sí mismos o a otros Novísimos, en una complicada red de citas que acaban por resultar innecesarias y superfluas. ${ }^{7}$ Con el tiempo, la mayoría de los escritores

6 De hecho, la amistad con Pedro Juan Gutiérrez es uno de los argumentos de Valle para mostrar su acercamiento del mundo marginal. Así, afirma, por ejemplo, que no habría podido escribir sus libros "si no hubiera fortalecido mi amistad con el escritor cubano Pedro Juan Gutiérrez, que puso ante mí muchas de las claves secretas del barrio donde vivíamos" (VALLE, 2007). Los dos escritores vivieron en la misma cuadra en Centro Habana.

7 Sobre la autorreferencialidad en los Novísimos, ver Valladares Ruiz, “Lo especial del periodo”. 
del grupo terminaron por desecharlas, siendo quizás Amir Valle el único que las ha mantenido. Para Annarella O'Mahony, en el caso de Valle, esta autorrepresentación tiene una triple finalidad: presentar a la intelectualidad cubana como "sujeto en la individualidad" (es decir, no a los intelectuales como colectivo, sino como individuos en un contexto específico), "denunciar la censura" y ubicar "a estos letrados como parte de los marginados ya no solo culturales, sino también sociales" (O’MAHONY, 2014, p. 57). Con esa triple finalidad, Valle incorpora en las novelas el personaje de Justo Marqués, alter ego del escritor y quien se encarga de poner en contacto a los dos protagonistas de la serie, Alain Bec y Alex Varga. ${ }^{8}$

Las alusiones a Justo Marqués en las sucesivas novelas de la serie van dando a conocer al lector sus éxitos editoriales (de Habana Babilonia primero, y a continuación del resto de novelas de la serie), su vasto conocimiento del mundo del jineterismo, sus problemas con la censura, su negativa opinión del periodismo oficial, el nombre de su esposa o incluso la calle donde vive, datos todos ellos que coinciden con los de Amir Valle.' Lamentablemente, estas alusiones son uno de los aspectos más irritantes de la serie, pues acaban por convertirse en obvia autopropaganda, que poco aporta a la narrativa. No obstante, vale la pena relacionarlas con el mencionado afán del autor de establecer un vínculo directo entre lo intradiegético y lo extradiegético, los planos de la literatura y la realidad. A través del personaje de Justo Marqués, Valle subraya la cualidad mimética de su narrativa, que no puede leerse sino como una comprobable transcripción literaria de la Cuba de principios de siglo. Puesto que en otros textos ha insistido igualmente en que los dos personajes principales de la serie también están basados en personas que conoció durante su investigación para Habana Babilonia, queda clara la importancia que el autor concede al verismo de sus novelas, quizás más cerca de lo que en inglés se ha venido a conocer como factional text que de la ficción pura. ${ }^{10}$

La primera novela de la serie, Las puertas de la noche, guarda una especial relación con Habana Babilonia de la cual toma fragmentos casi literalmente. ${ }^{11}$

8 Se podría aventurar que el nombre es un homenaje al escritor Justo Vasco y a Mario Conde, el teniente investigador de las novelas de Leonardo Padura, a quien en la novela Máscaras se le llama repetidamente Marqués.

9 Ver: Las puertas de la noche pp. 93 y 106; Si Cristo te desnuda pp. 90 y 108; Entre el miedo y las sombras pp. 16, 37, 89 y 149; Últimas noticias del infierno pp. 121 y 169; Santuario de sombras p. 136; Largas noches con Flavia pp. 56 y 102.

10 Alain Bec está basado en dos amigos de Amir (FERNÁNDEZ y OFFERDAHL, 2009, p. 156); Alex Varga en "la persona que me enseñó las claves secretas y las llaves públicas de la marginalidad cubana actual" (VALLE, 2003, p. 12). La palabra factional es un término acuñado recientemente a partir de la amalgama de fact (hecho) y fiction (ficción) para referirse a textos a caballo entre la ficción y la realidad.

11 La novela, finalista en 1998 del premio Distel Verlag, se publicó por primera vez en 2001 en Espańa. En 2002 salió la edición puertorriqueña, por la que cito. 
No en vano, teniendo en cuenta las fechas en que ambas fueron presentadas a sendos concursos, parecería que Valle las escribió simultáneamente o al menos en rápida sucesión.

En Las puertas de la noche el lector conoce a Alain Bec, teniente investigador de la Policía Nacional Revolucionaria y coprotagonista de la serie. A diferencia del Mario Conde de las novelas de Padura, del Leo Martín de Lorenzo Lunar o, en general, de los detectives privados del hard-boiled estadounidense, modelo al que se aproxima la serie, Alain Bec es un hombre de familia que vive con su esposa e hijo. Hijo de diplomático, "blanquito vivebien" (28), fue un "niñito mimado de Miramar" (44), el barrio habanero de las Embajadas y la población con mayores recursos económicos. Abiertamente racista y homófobo, va sufriendo una lenta conversión, gracias a la amistad que traba con el otro coprotagonista de la serie, Alex Varga. Como quedó mencionado anteriormente, el personaje de Alex Varga está basado en un individuo real del mismo nombre que hasta su muerte en 2002 fungía de oficioso alcalde de la zona en que vivía, defendiendo las leyes no escritas de la marginalidad. Como personaje, Varga fue detective privado en los cincuenta, llegando a trabajar para el mafioso Meyer Lansky; tras la Revolución dejó Cuba, a donde sin embargo retorna en la década de los setenta.

La dupla Bec - Varga resulta esencial, ya no solo como elemento narrativo, sino también para entender las cinco novelas como proyecto ideológico. Siguiendo el modelo de La Divina Comedia, la serie se puede leer como una visita guiada a los infiernos habaneros de la mano del guía Alex Varga. En un plano literal, el guiado es Alain Bec, quien al iniciar la serie posee un nulo conocimiento de la realidad de Centro Habana, Habana Vieja y los bajos fondos habaneros. En un plano más general, sin embargo, no cabe duda de que el guiado es el lector, quien solo gracias a la investigación policial puede adentrarse en una realidad a la que no llegan los "ciegos periodistas oficiales" (VALLE, 2003, p. 22). En este sentido, debe recordarse que es a través de Justo Marqués que Alain y Alex se conocen o, dicho de otra manera: es a través de Amir Valle que el lector llegará a entender la realidad cubana. De ahí la necesidad de insistir, un tanto machaconamente, a lo largo de la serie, en el extenso conocimiento que posee Marqués del mundo de la marginalidad, gracias la investigación realizada para escribir Habana Babilonia.

Relacionado con este punto, resulta importante enfatizar también el papel metonímico de La Habana en la serie. Recordemos que el proyecto primigenio se tituló sucesivamente Sade nuestro que estás en los cielos o Prostitución en Cuba; ${ }^{12}$ Habana Babilonia o Prostitutas en Cuba; y Habana Babilonia, la cara oculta de las jineteras, una cadena de títulos en los que resulta

12 Es el título en el primer manuscrito. Valle ha reconocido que aquel título era "horrible" y ha explicado cuándo lo cambió (TÁPANES, 2006). 
obvia la creciente importancia de una Habana que acaba por reemplazar a Cuba misma. Para Luis Pérez-Simón, la serie puede entenderse como una visión contracorriente de La Habana, la cual había desempeñado tradicionalmente el papel de metonimia idealizada de la nación, una especie de muestrario sublimado de la cubanidad. De tal modo, Valle estaría contribuyendo a la creación de un paradigma que daría entrada a nuevas visiones de La Habana (y por ende de Cuba) omitidas anteriormente (PÉREZ-SIMÓN, 2010, p. 155-156).

Desde un punto de vista similar, pero sin duda más crítico, Gilberto Padilla se refiere a "la ciudad porno-estéreo de Amir Valle" (PADILLA, 2014a, p.115). Como para Pérez-Simón, para Padilla existiría un tradicional "metarrelato monumental y edificante de la cubanidad", frente al cual se situaría "un discurso díscolo y liminal, que gravita hacia una asunción de la Isla como espacio bastardo, como resto y como ruina" (PADILLA, 2014a, p.116). Padilla, sin embargo, reprocha a los autores que cultivan esta tendencia ("postraumados", les llama) el convertir

el velorio de Cuba en una atracción especial, una puesta en escena vigente, una reserva natural: $;$ En directo con la realidad cubana! - dice su copla $-i$ Visiten este mundo disfuncional! ¡Concédanse el estremecimiento de la cuban experience! (PADILLA, 2014a, p.116).

Así percibido, el descenso a los infiernos dotaría al lector no de un papel de aprendiz de la realidad cubana, sino más bien de voyeur, de otro ajeno que se deleita contemplando miseria y degradación.

De manera semejante, la crítica cubana Odette Casamayor (2002) ha reprochado a Valle su tratamiento del racismo a lo largo de la serie, aspecto al que el autor concede especial relevancia desde la caracterización de la pareja protagonista: Alain es blanco y Alex es negro. Si por una parte Casamayor considera "la descripción del racista común un tanto caricatural" y la transformación de Alain "demasiado simple para resultar verosímil", más importante en el contexto de lo que venimos diciendo es la equiparación que hace entre las novelísticas de Amir Valle y Pedro Juan Gutiérrez, quienes, afirma, "apoyan a menudo su prosa en un deliberado regodeo en la miseria, que vinculan sin más a la delincuencia e incluso a veces al color de la piel" (CASAMAYOR, 2002, p.28 y 29). ${ }^{13}$

El propio Amir Valle es consciente de lo que considera una mala interpretación de su tratamiento del racismo en la serie, si bien parece atribuirlo

13 Para otra crítica similar del tratamiento del racismo en la serie ver Frauke Gewecke, para quien la conversión de Alain Bec "carece totalmente de fundamentación psicológica", menciona problemas asociados con el uso del estilo indirecto y censura la introducción de testimonios desconectados con la trama "de algún pobre negro que relata su historial delictivo" (GEWECKE, 2010, p. 233-235). 
a la renuencia oficial a aceptar y tratar el tema públicamente. En entrevista personal que mantuve con él en 2005 en La Habana, cuando ya se habían publicado las tres primeras entregas de la serie, el escritor afirmó que había decidido incluir en Las puertas de la noche "un personaje absolutamente racista para que algo despierte, para que la gente se moleste", incluso "a sabiendas de que en Cuba no lo iban a publicar". Puesto que el racismo era un tema que había aparecido muy esporádicamente, "Las puertas de la noche fue un golpetazo duro, que alguna gente no soportó, y pensó que era racista. Yo creo que, al contrario, aboga por otra cosa". Valle consideró que, en último término, el problema radicaba en el tratamiento de la prostitución infantil, un tema completamente tabú (VALLE, 2005). ${ }^{14}$

Si bien es posible que no le falte razón al autor, las críticas a su tratamiento del racismo, como hemos visto, no parten únicamente desde la oficialidad revolucionaria, y confieso haberme sentido incómodo ante determinados aspectos de la serie. El problema del racismo de los negros, por ejemplo, aparece sobredimensionado hasta el punto de parecer equiparado al racismo que sufren los negros, lo cual no solo es falaz, sino que convierte en chiste el gravísimo problema de la autoimagen negativa en la población afrocubana. La hipersexualización es un problema que alcanza tanto a mulatas (varias de las cuales son jineteras por su sublimado deseo sexual) como a los numerosos afrocubanos dotados de "mandarrias descomunales" (VALLE, 2002, p. 138).

Vale quizás la pena citar aquí a Stuart Hall, para quien la insistencia estereotipada y fetichista en determinadas características pretende convertirlas en marcadores de diferencia racial, hasta hacer de ellas equivalentes semánticos del cuerpo negro. Estos marcadores, que Hall identifica como "piel negra, labios gruesos, pelo rizado, penes tan grandes como catedrales" (HALL, 1996, p. 21), no son significados en sí, sino significantes que se mueven en un determinado régimen discursivo que les otorga un valor metonímico, claro. De tal modo, las referencias tanto a insaciables capacidades sexuales como a penes gigantescos consiguen perpetuar el mismo racismo que se quiere combatir. Es cierto, desde luego, que dichas menciones pueden focalizarse de modo que muestren el discurso racista de, por ejemplo, Alain Bec. En demasiadas ocasiones, sin embargo, no queda claro de dónde parten las afirmaciones racistas, que no cabe sino atribuir, como afirma Gewecke al narrador extradiegético y confiable (GEWECKE, 2010, p.233), el cual, por cierto, es la clave tras la que se halla el posicionamiento ético de las novelas. En otras ocasiones, además, solo se pueden atribuir a decisiones autorales

14 Con posterioridad, Valle ha afirmado que cuando el manuscrito de la novela fue rechazado por las editoriales habaneras Letras Cubanas y Extramuros, se le dijo que trataba un tema demasiado complicado y era "asquerosamente racista" (LÓPEZ BAO, 2012, p. 97). 
totalmente reprensibles, la más notable de las cuales, sin duda, es la escena de la violación con la que concluye "Últimos días del infierno", en la que el negro Mediometro "dueño de una de las mandarrias más asombrosas de toda la capital" procede a violar (pública y mortalmente), por orden de Alex Varga, al "blanquito" autor del asesinato que da lugar a la investigación policial (VALLE, 2005, p. 260 y ss.). Una reproducción de estereotipos raciales en toda regla.

Con todo, resulta evidente que, conforme avanza la serie, el dominio de la narrativa por parte del autor se acrecienta. La desproporcionada proximidad al modelo de Habana Babilonia en Las puertas de la noche disminuye en Si Cristo te desnuda, en la que se maneja con más acierto el suspense y gana en desarrollo el personaje de Alex Varga. Entre el miedo y las sombras, por su parte, da entrada a un lenguaje marginal más creíble e incrementa de nuevo la profundidad de Alex Varga (por cuanto Alain Bec prácticamente no aparece en toda la novela). ${ }^{15} \mathrm{Es}$, sin embargo, en la cuarta entrega, Santuario de sombras, donde el salto cualitativo es sobresaliente.

La novela presenta una compleja disposición que obliga al lector a jugar un papel mucho más activo que en el resto de la serie, al mismo tiempo que, inevitablemente, avanza tan desorientado como los propios personajes. La novela se abre con ocho páginas (tras las cuales comienza el primer capítulo), en las que, mediante fragmentos entrecortados y aparentemente inconexos en un principio, comprendemos que Mayra e Ignacio están atados, Samuel apunta a Ignacio con una pistola, Alain apunta con otra pistola al hermano de Samuel, Saúl, mientras que Alex Varga y Magnolia observan lo que ocurre. La escena se abandona de inmediato, volviendo a ella solo al final de la novela, construida, por tanto, sobre una estructura circular.

Los siguientes once capítulos constan de seis fragmentos cada uno, narrados a través de cada uno de los personajes principales, siempre en el mismo orden: Mayra (quien se vio obligada a ejercer la prostitución tras intentar salir ilegalmente de Cuba), Ignacio (cuya mujer y tres hijos fueron asesinados por el hermano de Saúl, Samuel, en una travesía ilegal hacia Miami), Alain, Magnolia (un homosexual travesti cuya pareja también murió a manos de Samuel), Alex y Saúl (alto funcionario en el Ministerio de Turismo cubano y traficante de personas entre Cuba y Miami). A través de estos fragmentos se narra colectivamente una investigación que culmina con la resolución de la escena con que se abre la novela.

De tal modo, Amir Valle consigue, al mismo tiempo, replicar y subvertir el modelo narrativo de la novela policial revolucionaria, basada siempre en

15 Amir Valle ha comentado que una de las metas de su serie era conseguir que cada novela tuviera su sello diferente y no hubiera un mismo estilo identificable en todas ellas (FERNÁNDEZ y OFFERDAHL, 2009, p. 161). Una de las formas en que lo consigue es variando el peso específico de los dos coprotagonistas en cada novela. 
un héroe colectivo (el pueblo), cuya colaboración resultaba imprescindible en las investigaciones de las fuerzas de Seguridad del Estado. En este caso, sin embargo, si bien el protagonismo recae de nuevo en un colectivo, lo es de antihéroes, marginales no integrados en el proceso revolucionario y que en ningún momento contemplan la posibilidad de que el sistema judicial cubano solucione su problema. Al respecto, el autor ha afirmado que la novela tiene algo de esquizofrénico, motivado por su deseo de "darle voz a los sin voz, de permitir que las voces de las víctimas de los errores de una sociedad se escucharan" (VALLE, 2013). A partir de una serie de entrevistas que sostuvo con personas que habían sobrevivido al tráfico de personas, decidió que había de escribir "una novela que fuera algo plural, una novela que fuera como un coro de voces sobre un mismo tema" (FERNÁNDEZ y OFFERDAHL, 2009, p. 158-159).

Debe enfatizarse en todo caso, como indica Shanna Lino, que el resultado es mucho "más que una mera polifonía de perspectivas o voces narrativas":

la multiplicidad de perspectivas, voces, personas gramaticales e incluso tiempos verbales en la narración de la novela difumina las líneas entre el bien y el mal o entre la culpa y la inocencia y subvierte el paradigma de la ley y el orden, al tiempo que se aproxima a la preocupación del neopolicial por la justicia, incluidas su existencia fuera de un marco legal (LINO, 2013, p.217. Traducción mía).

Es con esta novela, sin duda, con la que Valle consigue no solo sentirse libre para jugar con la estructura y denunciar determinados aspectos de la realidad cubana, sino también ofrecer un texto conmovedor, innovador y de enorme valía literaria.

Concluyo señalando que, a pesar de los problemas indicados, es evidente en la serie un claro proceso de aprendizaje que ha de apreciarse en su contexto. Tras décadas de policial revolucionario, Padura primero, Lorenzo Lunar y Amir Valle después, experimentan con las posibilidades de un género cuyos horizontes tratan de expandir para crear el neopolicial. Es posible que la salud de la que goza el género en Cuba hoy en día no hubiera sido posible sin la experimentación (y hallazgos) del descenso a los infiernos de Amir Valle. 
AÑEL, Armando. Censura y autocensura en la literatura cubana de los noventa: una observación y algunos apuntes, Revista Hispano Cubana, no 13, Madrid: Fundación Hispano Cubana, 2002, p. 71-78.

CASAMAYOR CISNEROS, Odette. "Negros de papel: Algunas apariciones del negro en la narrativa cubana después de 1959." Manuscrito inédito, 2002. Disponible en: $<$ https://www.academia.edu/15213059/Negros_de_papel_Algunas_apariciones_ del_negro_en_la_narrativa_cubana_despu\%C3\%A9s_de_1959>.

FERNÁNDEZ, Manuel \& OFFERDAHL, Emily. 'Yo no escribo novelas críticas; yo escribo novelas': Entrevista con Amir Valle, Hipertexto no 9, 2009, p. 153-66.

GEWECKE, Frauke. La 'nueva' novela policial cubana: Leonardo Padura Fuentes, Amir Valle, Lorenzo Lunar. En GEWECKE, Frauke. De islas, puentes y fronteras Estudios sobre las literaturas del Caribe, de la Frontera Norte de México y de los latinos en EE.UU. Madrid \& Frankfurt am Main: Iberoamericana-Vervuert, 2010, p. 221-43.

HALL, Stuart. The After-Life of Frantz Fanon: Why Fanon? Why Now? Why Black Skin, White Masks? En: The Fact of Blackness: Frantz Fanon and Visual Representation, editado por Alan Read. Londres: Institute of Contemporary Arts and International Visual Arts, 1996, p. 12-37.

HERNÁNDEZ, Rafael, et. al. ¿QQué significa ser marginal? En: Último Jueves. Los debates de Temas 1. La Habana: Unión, 2001, p. 83-108.

LINO, Shanna. In Search of Responsibility to/for the Other: Human Trafficking to the Florida and Iberian Peninsulas in Antonio Jiménez Barca and Amir Valle, Revista Canadiense de Estudios Hispánicos, no 38.1, 2013, p. 211-27.

LÓPEZ BAO, Orosman. Fraying at the Edges: Male Homosexuals, Female Prostitutes, and Suicides in Cuba's Post-Soviet Detective Fiction, Tesis de doctorado, Emory University, 2012.

O'MAHONY, Annarella. Historia y memoria en Cuba a través de la narrativa de Amir Valle en Habana Babilonia, Santuario de sombras y Las palabras y los muertos), Tesis de doctorado, University of Limerick, 2014.

PADILLA CÁRDENAS, Gilberto. Boxing, On Cuba Magazine, 2015. Disponible en: <http://oncubamagazine.com/columnas/boxing/>.

PADILLA CÁRDENAS, Gilberto. El factor Cuba. Apuntes para una semiología clínica, Temas no 80, 2014a, p. 114-20.

PADILLA CÁRDENAS, Gilberto. Sigue leyendo: todo Chavarría por un Padura, $O n$ Cuba Magazine, 2014b. Disponible en: <http://oncubamagazine.com/cultura/ todo-chavarria-por-un-padura/>.

PÉREZ-SIMÓN, Luis. Crónica de un tiempo anunciado. La novela negra de Amir Valle y Lorenzo Lunar Cardedo, Indicios, señales y narraciones. Literatura policíaca en lengua española. Ed. Rodrigues-Maura, Enrique. Innsbruck innsbruck university press, 2010, p. 153-71. 
SANTIESTEBAN, Ángel. Amir Valle: el escritor precoz, Los hijos que nadie quiso, 2015. Disponible en: <https://blogloshijosquenadiequiso.files.wordpress.com/2015/07/ entrevista-a-amir-valle-2015.pdf>.

TÁPANES LÓPEZ, Raúl. Amir Valle: Escribo de la marginalidad porque vivo en esos barrios... en la misma Cuba profunda que yo habito, Letralia no 153, 2006. Disponible en: <https://letralia.com/153/entrevistas01.htm>.

VALLADARES RUIZ, Patricia. Lo especial del periodo: políticas editoriales y movimiento generacional en la literatura cubana contemporánea, Neophilologus no 89, 2005, p. 383-402.

VALLE, AMIR. Entrevista personal. 6 de febrero de 2005.

VALLE, Amir. Brevisimas demencias. La narrativa joven cubana de los 90. La Habana: Extramuros, 2000.

VALLE, Amir. Si Cristo te desnuda. Santiago de Cuba: Oriente, 2001.

VALLE, Amir. Las puertas de la noche. San Juan de Puerto Rico: Plaza Mayor, 2002.

VALLE, Amir. Entre el miedo y las sombras. Granada: Zoela, 2003.

VALLE, Amir. Últimas noticias del infierno. En Vidas de oficio, El último tranvía y Últimas noticias del infierno. Editado por Fernando Martínez Laínez. Madrid: EDAF, 2005. 101-71.

VALLE, Amir. Santuario de sombras. Córdoba: Almuzara, 2006

VALLE, Amir. De jineteras a la serie "el descenso a los infiernos": derivaciones de la realidad a la ficción novelada, 2007. Disponible en: <http://amirvalle.com/ es/ensayo/de-jineteras-a-la-serie-el-descenso-a-los-infiernos-derivaciones-delarealidad-a-la-ficcion-novelada/>.

VALLE, Amir. Largas noches con Flavia. Córdoba: Almuzara, 2008.

VALLE, Amir. 'La voz de los sin voz' o el concierto desvelado de las víctimas de la marginalidad en la actual novela negra cubana, Festival Internacional Medellin Negro. Medellin, 2013. Disponible en: <http:// amirvalle.com/es/ensayo/la-voz-de-los-sin-voz-o-el-concierto-desveladode-las-victimas-de-la-marginalidad-en-la-actual-novela-negra-cubana/ > .

Carlos Uxó é professor no Departamento de Estudos Espanhóis e Latinoamericanos em Monash University, Austrália. Especialista em literatura cubana, suas linhas de investigação se centram no policial e no neopolicial. Também tem trabalhado no tema da representação dos personagens afrocubanos na narrativa posterior a 1990. Autor de multiplos artigos sobre este temas em revistas academicas e dos livros The Detective Fiction of Leonardo Padura Fuentes (2006) e Representaciones del personaje del negro en la narrativa cubana. Uma perspectiva desde os Estudios Subalternos (2010). Também tem publicado diversos artigos sobre as políticas de internet em Cuba.

E-mail: carlos.uxo@monash.edu 